\title{
İklim değişikliği strateji ve eylem planlarında havza yaklaşımı ve doğa temelli çözümler
}

\author{
Watershed approach and nature-based solutions in climate change strategies and action \\ plans
}

Erda ÇELER ${ }^{1}$ (D)
Yusuf SERENGIL ${ }^{2}$

${ }^{1}$ Orman Genel Müdürlüğü, Ankara

${ }^{2}$ İstanbul Üniversitesi-Cerrahpaşa, Orman Fakültesi, İstanbul

Sorumlu yazar (Corresponding author) Erda ÇELER

celererda@gmail.com

Geliş tarihi (Received)

07.06.2021

Kabul Tarihi (Accepted)

02.09.2021

Sorumlu editör (Corresponding editor) Filiz YÜKSEK

filiz6108@gmail.com

Atıf (To cite this article): Celer, E., Serengil, Y. (2021). İklim Değișikliği Strateji ve Eylem Planlarında Havza Yaklaşımı ve Doğa Temelli Çözümler . Ormancılık Araştırma Dergisi , 8 (2), 197 207. DOI: 10.17568/ogmoad.949294

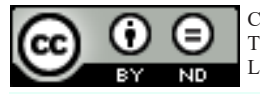

Commons Atıf Tïretilemez 4.0 Uluslararas isansı ile lisanslanmıștır.

\section{Öz}

Başta Birleşmiş Milletler İklim Değişikliği Çerçeve Sözleşmesi (BMIDÇS, https://unfecc.int) olmak üzere birçok uluslararası kuruluş iklim değişikliği ile mücadelede doğa temelli çözümleri (DTÇ) desteklemektedir. Bu çözümler, sürdürülebilirlikleri ve altyapı odak11 gri çözümlere kıyasla daha uygun maliyetli ve ekolojik faydaları nedeniyle son zamanlarda ön plana çıkmaktadır. DTÇ'nin iklim değişikliği strateji ve eylem planlarına daha yaygın şekilde dahil olması ormancılık sektörü için de önemli bir firsat olarak görülebilir. DTÇ ve havza yaklaşımının, iklim değişikliğine uyum ile yakından ilişkili olmasına karşın strateji ve planlarda yeterince yer bulmadığı düşüncesindeyiz. Çalışmanın amacı bu durumu, yani iklim değişikliği strateji/eylem planlarına havza ve DTÇ kavramlarının ne ölçüde yansımış olduğunu ortaya koymaktır. Çalışma kapsamında, küresel ölçekte 40 ülke ve 60 kentin iklim değişikliğine uyum ve azaltım planları analiz edilmiştir. Ayrıca Türkiye'de 16 kentin iklim değişikliği strateji/eylem planları bu kapsamda değerlendirilmiştir. İlk aşamada iklim değişikliği azaltım ve uyum stratejileri arazi kullanımı, ormancılık, havza yaklaşımı ve uyum yönlerinden incelenmiştir. Buradan elde edilen sayısal veriler meta-analiz yöntemi ile değerlendirilmiştir. Araştırma bulguları, iklim eylem planlarında, azaltım politika ve önlemlerinin uyuma nazaran daha geniş yer bulduğunu, havza kavramı ve doğa temelli çözümlere ise yeterince yer verilmediğini ortaya koymuştur.

Anahtar Kelimeler: İklim değişikliği, doğa temelli çözümler, havza

\begin{abstract}
Several organizations including the United Nations Framework Convention on Climate Change (UNFCCC, https://unfecc.int) are supporting nature-based solutions $(\mathrm{NbS}$ ) in combatting climate change. $\mathrm{NbS}$ are incentivized for their sustainability, ecologic benefits and higher cost-effectiveness compared to infrastructure-based solutions. The broader inclusion of $\mathrm{NbS}$ in climate change strategies and action plans can serve as an essential opportunity for the forestry sector. We think that although the watershed approach and $\mathrm{NbS}$ are closely related to the climate adaptation, they are neglected in plans and strategies. The aim of the study is to reveal to what extent the adaptation, basin, and $\mathrm{NbS}$ concepts are included in the climate change action/strategy plans of the countries and cities. Within the scope of the study, climate change adaptation and mitigation plans of 40 countries and 60 cities were analyzed on a global scale. In addition, climate change strategy/ action plans of 16 cities in Turkey were examined.As an initial step, climate change mitigation and adaptation strategies were investigated regarding land use, forestry, watershed approach, and adaptation. The data obtained were evaluated with the meta-analysis method. The results revealed that mitigation policies and measures had a broader place in the climate action plans than adaptation while watershed and $\mathrm{NbS}$ concepts have not been included appropriately.
\end{abstract}

Keywords: Climate change, nature-based solutions, watershed 


\section{Giriş}

Artan küresel sıcaklığın olumsuz etkileri belirginleştikçe, ülkeler ve şehirlerin sera gazı salımlarını azaltma yanında uyum kapasitelerini güçlendirme yönünde daha istekli hale geldikleri görülüyor (Bertoldi ve ark., 2018; Morgan, 2019). Öte yandan azaltım ve uyum kapasitesi ve eylemleri bakımından bölgesel anlamda önemli farklılıklar oluşmaktadır (Gunfaus ve Waisman, 2021). Avrupa ülke ve şehirleri iklim değişikliği ile mücadelede ağırlığ emisyon azaltımına verirken gelişmekte olan ülkelerde uyum eylemleri ön plana çıkmaktadır. Türkiye'nin strateji belgesi, iklim değişikliği eylem planı ve uyum eylem planı hazırlanmış olup bu belgelerde ormancılık sektörüne de yer verilmiştir (T.C. Çevre ve Şehircilik Bakanlığı (2010-2023); T.C. Çevre ve Şehircilik Bakanlığı (2011-2023)).

Hükümetlerarası İklim Değişikliği Paneli (İng. IPCC, https://www.ipcc.ch) AR5 raporu, iklim sisteminde insan etkisinin net olduğunu ortaya koymuştur. Raporda ayrıca, insan faaliyetleri sonucu iklim sistemi ne kadar bozulursa, insanlar ve ekosistemler için ciddi, yaygın ve geri döndürülemez risklerin ve uzun süreli değişikliklerin o denli fazla olabileceği vurgulanmıştır (IPCC, 2014). Paris İklim Anlaşması, New York Ormanlar Bildirgesi, Tropikal Orman İttifak1 2020 ve Bonn Mücadelesi gibi çeşitli taahhüt ve stratejiler, orman/arazi kullanımının ve doğal kaynakların azaltım ve adaptasyondaki rolünü desteklemektedir. Ayrıca BM 2017-2030 Orman Stratejik Planında, ormanların ve ilişkili ekosistemlerin sürdürülebilir bir şekilde yönetilmesi, ormansızlaşma ve orman bozulumunun durdurulması yönünde her düzeyde faaliyetler yürütülmesine yönelik küresel bir çerçeve ihtiyacının altı çizilmiştir (Gunfaus ve Waisman, 2021).

Kentler, enerji tüketiminin ve sera gazı emisyonlarının başlıca kaynağı durumundadır. Kentsel alanlardaki bina, insan ve enerji yoğunluğu nedeniyle toplam salım miktarı yüksek görünürken, doğru bir kentleşme şablonunda kişi başı salım değerleri düşürülebilir (Grafakos ve ark., 2019). Aslında kentsel alanların iklim değişikliği ile mücadelede önemli bir işleve sahip olduğu anlaşılmış olmakla beraber eylemlerin başarısı ve etkililiği hakkında çok az şey bilinmektedir (Salvia ve ark., 2021). Zira şehirler için küresel ölçekte düzenli ve etkin bir sera gazı izleme sistemi henüz geliştirilmemiştir.

Mikro-iklimin düzenlenmesi, kentsel 1s1 adası etkisini azaltmak bakımından yeşil alanların sağladığı başlıca ekosistem hizmetleri arasındadır. Sıcaklık artışının Münih (Almanya) şehrinde yayaların ısı kaynaklı stresini gelecek on yılda \%6 artıracağ1, buna karşın yol kenarı ağaçlarının fizyolojik eş- değer sıcaklığ $1 \% 10-13$ azaltabileceği tahmin edilmektedir (Zölch ve ark., 2016). Cohen-Shacham ve ark. (2019) tarafından DTÇ “doğal veya değiştirilmiş ekosistemleri korumak, sürdürülebilir bir şekilde yönetmek ve restore etmek için toplumsal zorlukları (örneğin iklim değişikliği, gıda ve su güvenliği veya doğal afetler) etkili ve uyumlu bir şekilde ele alırken aynı zamanda insan refahı ve biyolojik çeşitlilik faydaları sağlayan eylemler" olarak tanımlanmıştır.

DTÇ yaklaşımları daha iyi bir yaşam ortamı için ekosistemlerin dayanıklılığını, yenileme kapasitelerini ve ekosistem hizmetlerinin etkinliğini artt1rarak sürdürülebilir kalkınmayı hedeflemektedir.

DTÇ tanımından da anlaşılacağı gibi şemsiye bir kavramdır ve yeşil altyapıya yönelik araçlarla kombine edildiğinde ormancılık ve arazi kullanma konulu birçok projeye uyarlanabilir. Hatta etkin bir azaltım ve uyum çerçevesi için ekosistem hizmetleri ile entegre biçimde tüm ormancılık politika ve programlarına dahil edilebilir. Cohen-Shacham ve ark. (2019) tarafından verilen bazı DTÇ örnekleri şunlardır:

- Taşkın riskini azaltmak üzere akarsu koridorunun restorasyonu

- Taşkın kontrolü ve biyoçeşitliliğin korunması için sulak alan ve çeltik tarlalarının sürdürülebilir yönetimi

- Su basar ormanlarının korunması ve restorasyonu,

- Fırtına zararını azaltmak için Meksika körfezinde bariyer adalarının ve sulak alanların korunmas1

- Barselona (İspanya) yeşil altyapı ve biyoçeşitlilik planının geliştirilmesi

- Tacaná havzasında (Meksika ve Guatemala) sınır aşan suların ekosistem bazlı önlemlerle yönetilmesi

Kısacası DTÇ su ile ilgili birçok meselede kullanılma potansiyeline sahip doğal çözümleri kapsamakta ve dolayısıyla havza yaklaşımını öngörmektedir. Havza yönetimi hidrolojik döngüyü ekolojik perspektifte ele alan bir ormancılık disiplinidir ve havza yaklaşımını esas almaktadır. Bunun anlamı, hangi ölçekte olursa olsun (matris, peyzaj, havza vb.) çevre sorunlarına ekolojik bir çözüm vizyonu getirilebilmesidir. Dahası havza yaklaşımı bir çevre sorununun neden sonuç düzleminde değerlendirilmesini sağlayabilir. Çünkü aşağı havza kesimiyle ilgili sorunlar (örn. taşkın, heyelan) çok büyük olasılıkla yukarı havzadaki nedenlerle (ormansızlaşma, tarım vb.) açıklanabilmektedir (Sunde ve ark., 2018). 
Buraya kadar anlatılanlar kısaca özetlenecek olursa, iklim değişikliği ve çevre ile ilgili sorunların hemen tümü hidrolojik döngü ile ilişkilidir, dolayısıyla havza yaklaşımı ile anlaşılabilir ve çözümlenebilir. Çözüm aşamasında ise ister DTÇ olarak adlandırılsın isterse geleneksel tanım ve kavramlarla ifade edilsin ekolojik çözümlerin kullanılması sürdürülebilirlik anlamında gereklidir.

Ülkemizde iklim değişikliği eylem planları birçok açıdan ele alınmıştır. Örneğin:

- İklim değişikliği ve iklim politikaları (Özel ve ark., 2011)

- AB iklim değişikliği politikaları (Altunok ve Altunok, 2016)

- İklim değişikliği ile mücadelede yerel yönetimlerin rolü: Seattle örneği (Oğuz, 2010),

- İklim değişikliğinin küresel, bölgesel ve kentsel etkileri (Kahraman ve Şenol, 2018)

- Kentsel iklim değişikliği yönetişimi (Demirci,
2015) irdelemiştir. Fakat ülkemizdeki iklim değişikliği strateji ve eylemlerini uluslararası örnekleriyle karşılaştıran ve doğal bazlı çözümlere odaklanan bir araştırmaya rastlanmamaktadır

Bu makalede DTÇ ve bununla ilişkili havza yaklaŞımının ulusal ve kentsel iklim değişikliği strateji/ eylem planlarına ne ölçüde dahil edildiği konusu meta analiz ile irdelenmiştir.

\section{Materyal ve yöntem}

\subsection{Materyal}

Çalışma kapsamında ülkeler ve kentsel alanlar için hazırlanmış ulusal ve uluslararası iklim değişikliği azaltım ve uyum stratejileri, arazi kullanımı, ormancılık ve uyum yönlerinden incelenmiştir. Bunun için ülkelerin ve kentlerin iklim değişikliği ile mücadele eylem ve uyum/strateji planları ilgili web sayfalarından derlenmiş, incelenmiş ve analiz edilmiştir. Bu kapsamda verilerin değerlendirilmesi için aşağıdaki bilgilerden yararlanılmıştır (Tablo 1).

Tablo 1. Ülke ve kent bazında uluslararası strateji/eylem planlarındaki bilgiler

Table 1. Information in international strategy/action plans on a country and city basis

\begin{tabular}{ll}
\hline \multicolumn{1}{c}{ Bölgeler/Kıtalar } & $\begin{array}{c}\text { Ülkelerin ve kentlerin iklim değişikliği ile mücadele eylem ve } \\
\text { stratejileri hakkında araştııılan bilgiler }\end{array}$ \\
\hline Avrupa & $\begin{array}{l}\text { İklim Değişikliği Eylem Planı var mı? } \\
\text { Güney Amerika }\end{array}$ \\
Afrika & İkum Eylem Planı ve/veya Strateji Planı var mı? Değişikliği Eylem Planı "uyum”u kapsıyor mu? \\
Asya & 2030 yılı ormancılık azaltım hedefi var mı? \\
Basra Körfezi & Uyum eylemlerin kaçı ormancılıkla ilgili? \\
Kuzey Amerika & Eylem Planında Havza Kavramı geçiyor mu? \\
Okyanusya & Orman sektörü ile ilgili Uyum eylemlerin kaçı NbS ile ilgili? \\
\hline
\end{tabular}

\subsection{Yöntem}

Örneklemin seçimi ülkelerin ve kentlerin iklim değişikliği strateji/eylem planları ayrıntılı bir tarama sürecine dayanmaktadır. Örneklemde toplam 60 ülke, 60 şehir ve 16 Türkiye şehrinin kentsel iklim değişikliği strateji/eylem planları gözden geçirilmiş ve değerlendirilmiştir.

Seçilen ülke ve kentlerde ağırlık Avrupa'da olmuş, bunu Asya kıtası takip etmiştir (Tablo 2).

Türkiye'de ise 16 büyük şehrimizin (Denizli, Gaziantep, İstanbul, Kocaeli, Antalya, İzmir, Muğla, Bursa, Kahraman Maraş, Manisa, Trabzon, Kayseri, Sakarya, Mersin, Hatay ve Erzurum) iklim değişikliği strateji/eylem planları gözden geçirilmiş ve değerlendirilmiştir.

\section{Bulgular}

\section{1. Ülke bazında iklim değişikliği eylem planı ve/veya strateji belgeleri}

Avrupa, Afrika, Asya ve Okyanusya bölgelerinde seçilen ülkelerinin tamamında, Güney Amerika ve Kuzey Amerika kıtalarında seçilen ülkelerin \%75'inde ve Körfez bölgesinde seçilen ülkelerin \%40'ında İklim Değişikliği Eylem Planı (İDEP) mevcuttur (Şekil 1). ABD'de ise eyalet bazında İDEP mevcuttur.

İklim Değişikliğine Uyum Strateji ve/veya Eylem Planı (USEP) ise Avrupa, Asya ve Okyanusya bölgelerinde seçilen ülkelerinin tamamında, Güney Amerika ve Kuzey Amerika kıtalarında seçilen ül- 
Tablo 2. Analiz edilen bölgeler ve seçilen ülke ve kentlerin sayısı

Table 2. Number of analyzed regions and selected countries and cities

\begin{tabular}{|c|c|c|c|c|}
\hline $\begin{array}{l}\text { Bölgeler/ } \\
\text { Kitalar }\end{array}$ & $\begin{array}{l}\text { Ülke } \\
\text { say1s1 }\end{array}$ & $\begin{array}{c}\text { Kent } \\
\text { say1s1 }\end{array}$ & Ülkeler & Kentler \\
\hline Avrupa & 23 & 31 & $\begin{array}{l}\text { Türkiye, Fransa, İspanya, İtalya, } \\
\text { İrlanda, İsviçre, İsveç, Norveç, Da- } \\
\text { nimarka, Estonya, Rusya, Leton- } \\
\text { ya, Litvanya, Bulgaristan, Yuna- } \\
\text { nistan, Romanya, Polonya, Çekya, } \\
\text { Slovakya, Slovenya, Avusturya, } \\
\text { İngiltere ve Almanya }\end{array}$ & $\begin{array}{l}\text { İstanbul, Paris, Barselona, La Coruña, Mur- } \\
\text { cia, Roma, Londra, Birmingham, Dublin, } \\
\text { Amsterdam, Rotterdam, Atina, Berlin, Frank- } \\
\text { furt, Kopenhag, Stockholm, Uppsala, Oslo, } \\
\text { Tallinn, Lizbon, Porto, Varşova, Prag, Ljubl- } \\
\text { jana, Gent, Brüksel, Tiran, Viyana, Helsinki, } \\
\text { Oulu, Zagreb }\end{array}$ \\
\hline $\begin{array}{l}\text { Güney } \\
\text { Amerika }\end{array}$ & 8 & 3 & $\begin{array}{l}\text { Şili, Kolombiya, Venezuela, Peru, } \\
\text { Brezilya, Arjantin, Paraguay ve } \\
\text { Uruguay }\end{array}$ & Rio de Janeiro, Buenos Aires ve Medellín \\
\hline Afrika & 8 & 5 & $\begin{array}{l}\text { Kenya, Uganda, Gana, Tanzanya, } \\
\text { Etiyopya, Namibya, Kongo Cum- } \\
\text { huriyeti ve Zimbabve }\end{array}$ & $\begin{array}{l}\text { Cape Town, Johannesburg, Rabat, Accra ve } \\
\text { Addis Ababa }\end{array}$ \\
\hline Asya & 9 & 13 & $\begin{array}{l}\text { Tayland, Japonya, Vietnam, Hin- } \\
\text { distan, Çin, Filipinler, Endonezya, } \\
\text { Güney Kore ve Singapur }\end{array}$ & $\begin{array}{l}\text { Pekin, Shangay, Jilin City, Wuhan, Tokyo, } \\
\text { Osaka, Bangkok, Ho Chi Minh, Ahmedabad, } \\
\text { Bhopal, Putrajaya, Mingeçevir, Batum }\end{array}$ \\
\hline Basra Körfezi & 6 & 1 & $\begin{array}{l}\text { Suudi Arabistan Krallığı, Katar, } \\
\text { Umman, Ürdün, Irak ve İran }\end{array}$ & Riyad \\
\hline $\begin{array}{l}\text { Kuzey ve Orta } \\
\text { Amerika }\end{array}$ & 4 & 5 & $\begin{array}{l}\text { Amerika Birleşik Devletleri, Ka- } \\
\text { nada, Meksika ve Honduras }\end{array}$ & $\begin{array}{l}\text { Portland, Seattle, Atlanta, Ontario, Londra } \\
\text { (Kanada) }\end{array}$ \\
\hline Okyanusya & 2 & 2 & Avustralya ve Yeni Zelanda & Sidney ve Melbourne \\
\hline
\end{tabular}

\section{İDEP}
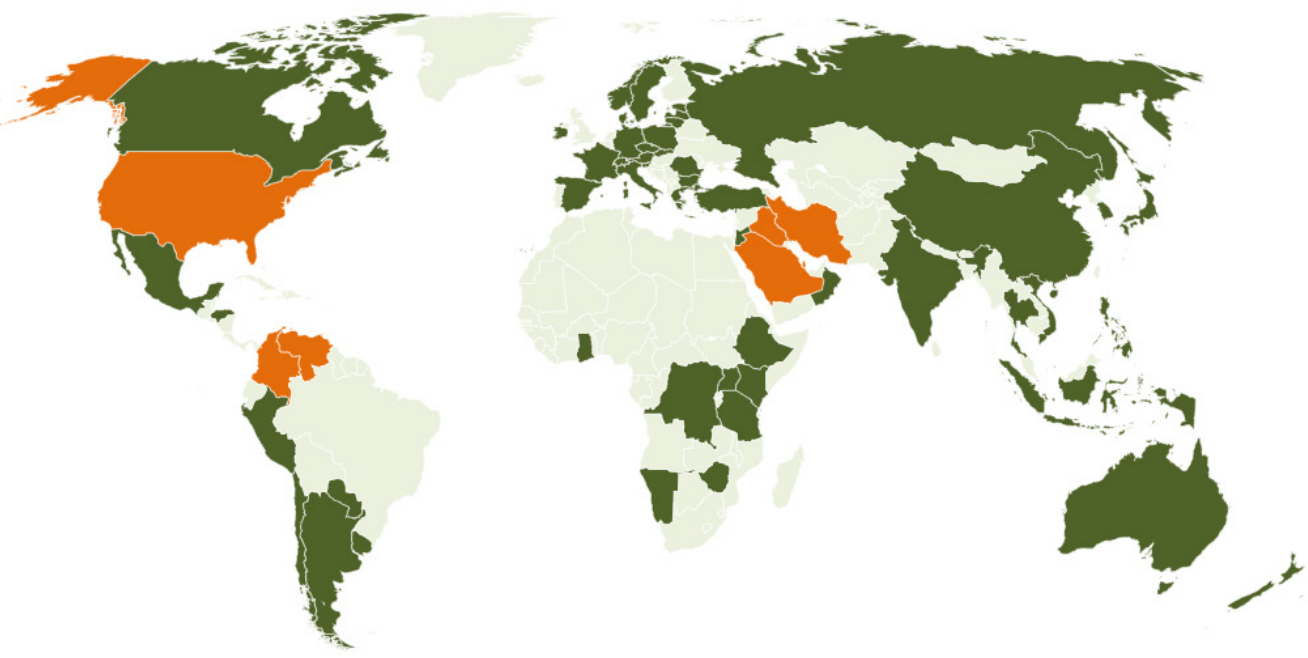

Şekil 1. Ulusal ölçekte iklim değişikliği eylem planı olan ve olmayan ülkeler (koyu yeşil- İDEP olan ülkeler, turuncu- İDEP olmayan, açı yeşil - veri olmayan ülkeler)

Figure 1. Countries with and without a national climate change action plan (dark green - countries with CCAP, orange - without CCAP, light green - countries without data)

kelerin \%75'inde, Afrika kıtasında seçilen ülkelerin \%87,5'inde ve Körfez bölgelerinde seçilen ülkelerinin \%16,66'sında mevcuttur (Şekil 2). ABD'de ise eyalet bazında iklim değişikliğine USEP mevcuttur.
Güney Amerika ve Okyanusya bölgelerinde seçilen ülkelerin İklim Değişikliği Eylem Planlarında sadece azaltım eylemleri yer almış, "uyum" konusuna yer verilmemiştir. Avrupa kıtasında seçi- 


\section{USEP}
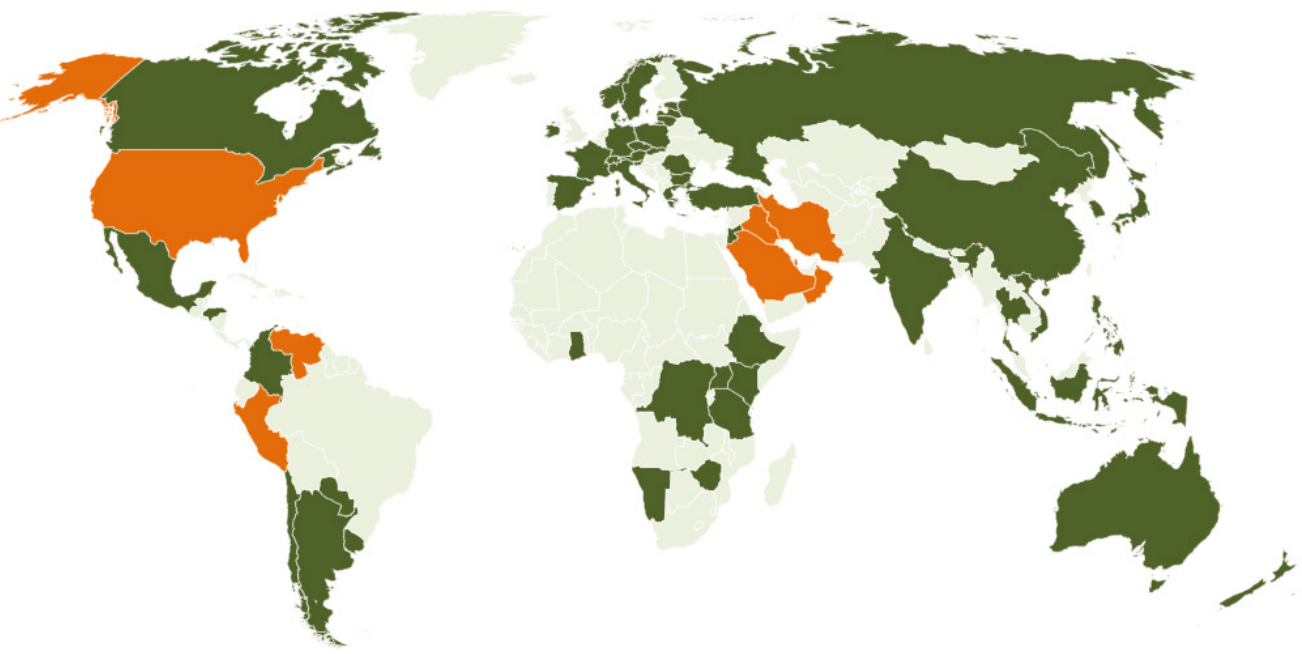

Şekil 2. Ulusal ölçekte iklim değişikliği uyum strateji/eylem planı olan ve olmayan ülkeler (koyu yeşil- USEP olan ülkeler, turuncu- USEP olmayan, açık yeşil - veri olmayan ülkeler)

Figure 2. Countries with and without a national climate change adaptation strategy/action plan (dark green countries with USEP, orange - without USEP, light green - countries without data)

len ülkelerin ise $\% 8,7$ 'si, Afrika kıtasında seçilen ülkelerin \%12,5'i, Asya kıtasında seçilen ülkelerin \%11,1'i, Körfez bölgesinde seçilen ülkelerin \%16,7'si ve Kuzey Amerika kıtasında seçilen ülkelerin \%25'inde İklim Değişikliği Eylem Planlarında "uyum" konusu yer almıştır.

İDEP'ler incelendiğinde 2030 yılı ormancılık azaltım hedefi Okyanusya bölgesinde seçilen ülkelerinin tamamında yer almaktadır. Avrupa kıtasında seçilen ülkelerinin \%82,6's1, Güney Amerika ve Kuzey Amerika kıtalarında seçilen ülkelerinin $\% 50$ 'si, Afrika kıtasında seçilen ülkelerinin \%37,5’i ve Asya kıtasında seçilen ülkelerinin \%33,3'ünde 2030 y1lı ormancilık azaltım hedefi bulunmaktadır. Körfez bölgesinde seçilen ülkelerde ise 2030 yılı ormancılık azaltım hedefi bulunmamaktadır.

İklim Değişikliği Eylem Planlarında "havza" kavramı Afrika kıtası ülkeleri hariç geniş biçimde yer almamaktadır (Şekil 3). Afrika kıtasında incelenen ülkelerin \%87,5'inde havza kavramı bir şekilde yer alırken Avrupa kıtasında seçilen ülkelerin \%43,4'ünde, Güney Amerika kıtasında seçilen ülkelerin \%50'sinde, Asya kıtasında seçilen ülkelerin \%44,4'ünde, Körfez bölgesinde seçilen ülkelerin \%16,6'sında ve Kuzey Amerika kıtasında seçilen ülkelerin \%50'sinde "havza" kavramı yer bulmuştur. Okyanusya bölgesinde ise seçilen ülkelerin IDEP'de "havza" kavramı yer almamaktadır. Havza kavramı genellikle hidrolojik afetler ve sonuçla- rı ile ilgili eylemlerin içeriğinde bahsedilmektedir. Örneğin havza bazında planlamanın önemi ve su kaynaklarının korunması ile ilgili eylemler önerilmektedir.

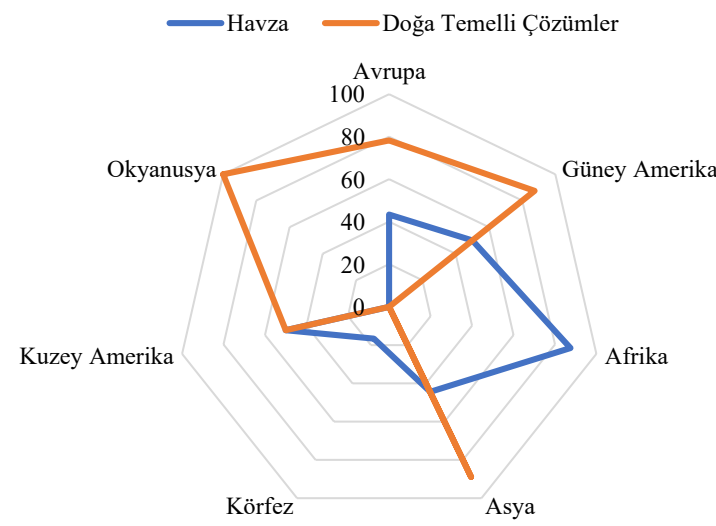

Şekil 3. Havza ve Doğa Temelli Çözümler kavramlarının dahil edildiği eylem planlarına sahip ülkelerin yüzdeleri

Figure 3. Percentage of countries with action plans incorporating the concepts of Watershed and Naturally Based solutions

Doğa Temelli Çözümler (DTÇ) ise yaygın olarak Okyanusya ülkelerinin tümünde, Avrupa kıtasında \%78,3'ünde, Güney Amerika kıtasında \%87,5'inde ve Asya kıtasında \%88,9'unda ülke planlarında yer alırken, Kuzey Amerika kıtasında seçilen ülkelerin ise \%50'sinde yer bulmuştur (Şekil 3). 


\subsection{Kent bazında iklim değişikliği eylem planı ve/veya strateji belgeleri}

İklim Değişikliği Eylem Planı (IDEP) Avrupa, Körfez, Kuzey Amerika ve Okyanusya bölgelerinde seçilen şehirlerin tamamında mevcuttur. Güney Amerika kıtasında seçilen şehirlerin \%66,7'si, Afrika kıtasında seçilen ülkelerin \%60`1 ve Asya kıtasında seçilen şehirlerin ise \%76,9'unda mevcuttur (Şekil 4).

İklim Değişikliği Uyum Strateji ve/veya Eylem Planı (USEP) ise Okyanusya bölgelerinde seçilen şehirlerin tamamında, Kuzey Amerika kıtasında seçilen şehirlerin \%20'sinde, Asya kıtasında seçilen şehirlerin \%30,8'inde, Afrika kıtasında seçilen şehirlerin \%40'ında, Güney Amerika'da seçilen şehirlerin \%33,3'ünde ve Avrupa kıtasında seçilen şehirlerin \%80,6'sında mevcuttur. Fakat Körfez bölgelerinde seçilen șehirlerin hiçbirinde İklim Değişikliği Uyum Strateji ve/veya Eylem Planı (USEP) bulunmamaktadır.

Avrupa kıtasında seçilen şehirlere ait IDEP'lerinin \%22,58'i, Asya kıtasında seçilen șehirlerin \%7,69'u ve Kuzey Amerika kıtasında seçilen şehir-

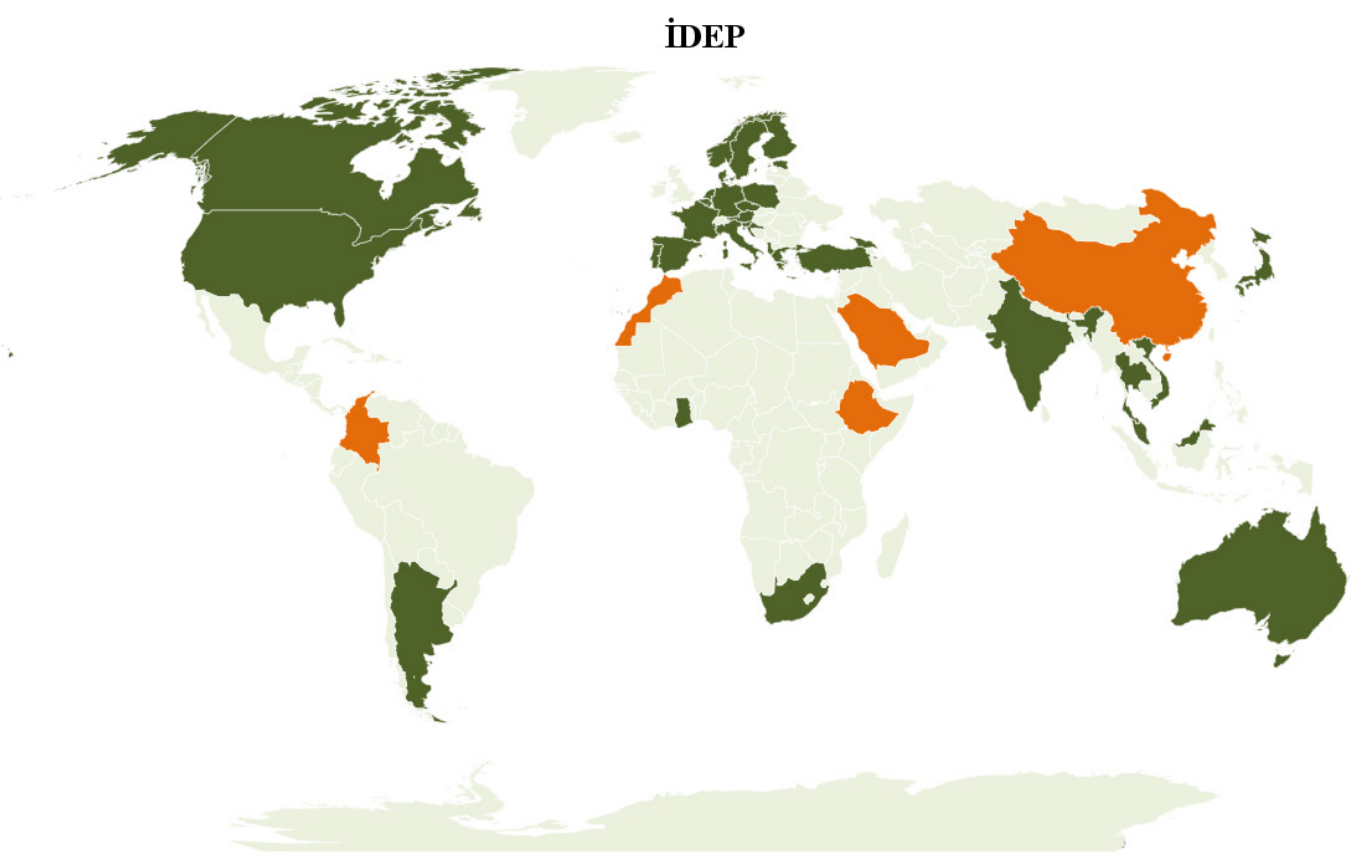

Şekil 4. Seçili kentlerdeki iklim değişikliği strateji ve/veya eylem planlarının bulunup bulunmama durumu (koyu yeşil- IDEP olan, turuncu- IDEP olmayan kentler, açık yeşil - veri olmayan ülkeler)

Figure 4. Availability of climate change action/strategy plans in selected cities (dark green - cities with IDEP, orange - cities without IDEP, light green - countries without data)

lerin \%80’inde İklim Değişikliği “uyum” konusunu kapsamaktadır. Ancak Güney Amerika, Afrika, Körfez ve Okyanusya bölgelerinde seçilen şehirlerin hiçbirinde İklim Değişikliği Eylem Planlarında "uyum" konusu yer almamaktadır.

İDEP'ler incelendiğinde 2030 y1lı ormancılık azaltım hedefi Avrupa kıtasında seçilen şehirlerin \%19,35’i, Kuzey Amerika kıtasında seçilen şehirlerin \%20'si ve Okyanusya bölgesinde seçilen şehirlerin \%50'sinde yer almaktadır. Fakat Güney Amerika, Afrika, Asya ve Körfez bölgesinde seçilen şehirlerin 2030 yılı ormancılık azaltım hedefi bulunmamaktadir.

İklim Değişikliği Eylem Planı (IDEP)'nda "havza" kavramı araştırılmış ve Avrupa kıtasında seçilen şehirlerin \%29'unda, Güney Amerika kitasında seçilen şehirlerin \%33,3'ünde, Afrika kıtasında seçilen şehirlerin \%20'sinde, Asya kıtasında seçilen şehirlerin \%23,1'inde, Kuzey Amerika kıtasında seçilen şehirlerin \% 80'inde ve Okyanusya bölgesinde seçilen şehirlerin \%50'sinde "havza” kavramı geçmektedir. Fakat Körfez bölgesinde seçilen şehirlerin IDEP'de "havza" kavramı geçmemektedir (Şekil 5).

Doğa Temelli Çözümler (DTÇ) ise Avrupa kıtasında seçilen şehirlerin \%38,7'si, Asya kıtasında seçilen şehirlerin \%7,7'si, Kuzey Amerika kıtasında seçilen şehirlerin \%20'si ve Okyanusya bölgesinde seçilen şehirlerin \%50'sinde yer almaktadır. Fakat Güney Amerika, Afrika ve Körfez bölgelerinde seçilen şehirlerin İklim Değişikliği Uyum eylemleri 
DTÇ ile ilgili değildir (Şekil 5).

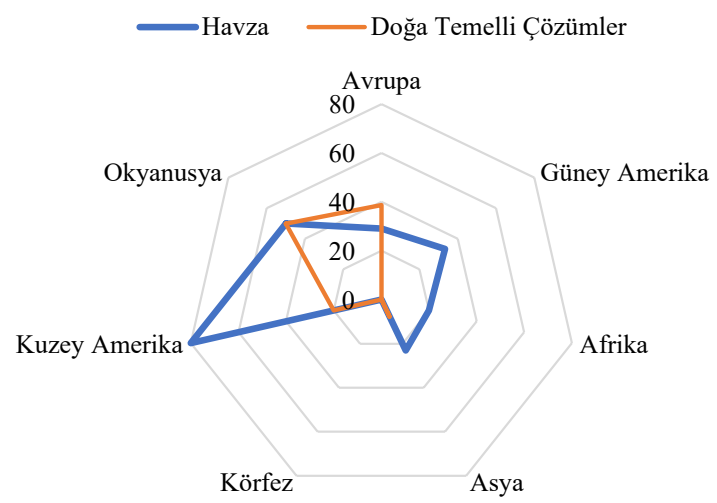

Şekil 5. Havza ve Doğa Temelli Çözümler kavramlarının dahil edildiği eylem planlarına sahip kentlerin yüzdeleri

Figure 5. Percentage of cities with action plans that include the concepts of Basin and Naturally Based Solutions

\subsection{Türkiye'de kentlerin iklim değişikliği eylem planı ve/veya strateji belgeleri}

Türkiye'de İklim Değişikliği Eylem Planı (IDEP) hazırlamış olan büyükşehirlerin oranı \%13,6'dır. IDEP olan iller ile hazırlık aşamasında olanlar değerlendirme kapsamına alınmıştır (Şekil 6).
Türkiye'de iklim değişikliği eylem planı hazırlanmış iller Antalya, Bursa, Denizli, Gaziantep, Hatay, İstanbul, İzmir, Kahramanmaraş, Kocaeli, Muğla ve Trabzon'dur.

Türkiye'de iklim değişikliği eylem planı hazırlık aşamasında olan iller ise Erzurum, Kayseri, Manisa, Mersin ve Sakarya'dır.

İklim Değişikliği Uyum Strateji ve/veya Eylem Planı (USEP) ise Türkiye'de seçilen şehirlerin $\% 12,5$ 'inde mevcut, \%31,5'inde ise hazırlık aşamasindadir.

İklim Değişikliği Eylem Planında Türkiye'de seçilen şehirlerin \%37,5'i İklim Değişikliği “uyum” konusunu kapsamaktadır. Ancak bunların \%31,5’i hazırlık aşamasındadır.

İDEP'ler incelendiğinde 2030 y1lı ormanc1lik azaltım hedefi Türkiye'de seçilen şehirlerin $\% 18,75$ 'inde yer almaktadır, \%31,5'i ise hazırlık aşamasındadır.

Öte yandan Türkiye'de seçilen şehirlerin İDEP'lerinin \%31,25'inde "havza" kavramı geçtiği görülmüştür. Doğa Temelli Çözümler (DTÇ) ise seçilen şehirlerin \%12,5'inde yer almaktadır.

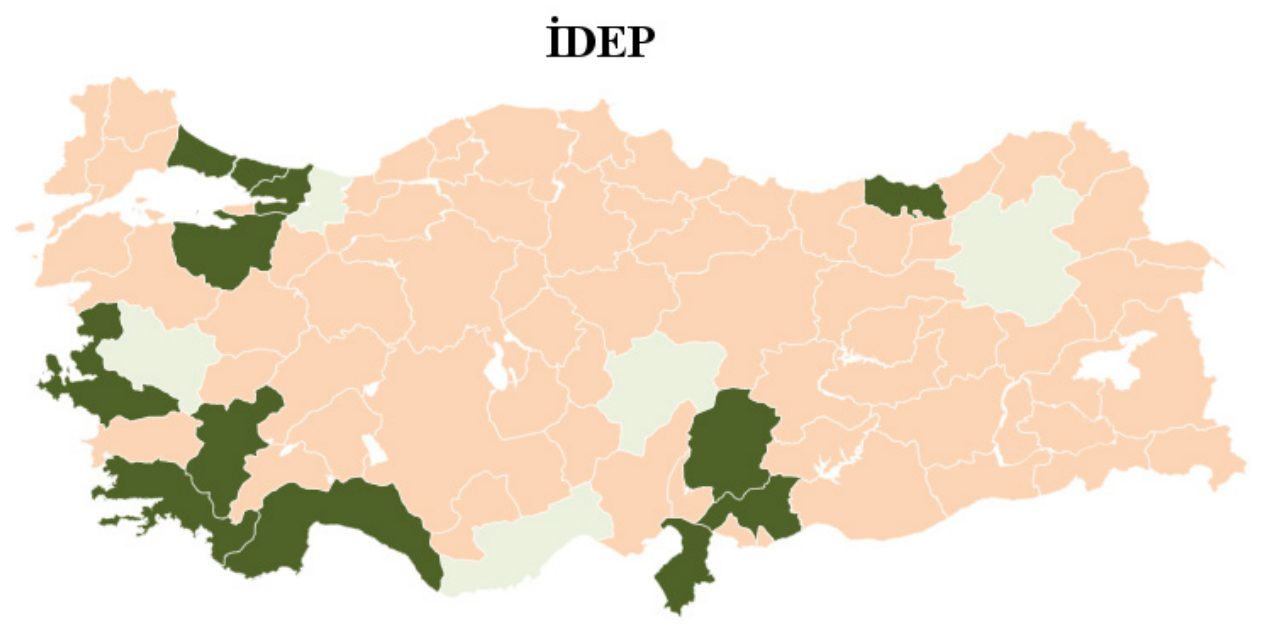

Şekil 6. Türkiye'deki kentlerde iklim değişikliği eylem planlarının durumu (koyu yeşil- IDEP olanlar, açık yeşilhazırlık aşamasındaki kentler, somon rengi - veri olmayan kentler)

Figure 6. Climate change action plans in cities in Turkey (dark green - IDEP ones, light green - cities in preparation, salmon color - cities without data)

\section{Tartışma ve Sonuç}

Ekosistem hizmetlerini artırıcı doğa temelli çözümlerin iklim değişikliği ile mücadelede verimli bir azaltım ve uyum çerçevesi için tüm orman ve arazi kullanımı politika ve programlarına entegre edilmesi gerekir. Diğer bir deyişle, ormancılık ve arazi kullanım politika/programları, ekosistem hizmetlerini de dikkate alarak sürdürülebilir ve doğa temelli çözümlere dayanmalıdır. Bu aynı zamanda ekosistem yaklaşımına ilişkin anlayışımıza da uygundur. Ormanlar ve diğer arazi kullanımları ekosistemlerin bir parçasıdır ve direnci ve uyumu güçlendirecek şekilde yönetilmelidir. Ekosistem 
direnci doğal veya yönetilen bir ekosistemin diş baskılara dayanma ve zaman içinde bozulma öncesi durumuna geri dönme kapasitesidir (Thompson ve ark., 2009). Ağaçlandırmalar ve müdahale görmüş ormanlar, genel olarak azalan biyolojik çeşitlilikleri nedeniyle, iklim değişikliğine bağlı büyük ölçekli kayıplar için birincil ormanlara göre daha büyük dış etkiler ve risklerle karşı karşıya kalacaktır. Bu nedenle, bir orman ekosisteminin dayanıklılığg, orman yönetimi tarafından şekillendirilen biyolojik çeşitlilik, yapı ve köken ile ilişkilidir.

Arazi kullanımı ve ormancılık, su ve doğal bazlı çözümlerle ilgili olduğundan havza yönetimi yaklaşımında veya perspektifinde ele alınmalıdır. $\mathrm{Bu}$ yaklaşım su miktarının/kalitesinin iyileştirilmesi, sellerin azaltılması, habitat kalitesi ve miktarının iyileştirilmesi ve diğer hizmet ve faydalardaki artış hedeflerine katkıda bulunmasını sağlar (WAH, 2014). Havzalar hidrolojik/ekolojik sistemlerdir, bu nedenle herhangi bir arazi kullanımı sorunu tek başına değil, sistemin bir parçası olarak ele alınır. Ekosistem hizmetleri ve doğal bazlı çözümlerle ilgili araştırmaların havza bazında inşa edilmesi gerekir (Serengil, 2018).

İklim değişikliği, günümüzün en geniş kapsamlı ve karmaşık çevre sorunlarından biri olarak kabul edilmektedir. Tüm küresel değerlendirmeler (NOAA, AR5 vb.) küresel ısınmanın yavaşlamadığını, aksine diğer insan kaynaklı stres kaynaklarıyla (kentleşme, hava kirliliği vb.) birleşerek etkilerini artırdığını ortaya koymaktadır. İklim değişikliği ile mücadele küresel bir çabayı gerektirmektedir. Fakat ülkelerin bu mücadeleye verdikleri katkı seviyesi çok değişkendir. BMIDÇS bunu "ortak ancak farklılaştırılmış sorumluluk" adı verilen bir ilkeyle tanımlamaktadır (Wang ve ark., 2018). Dolayısıyla, Paris İklim Anlaşmasında ifade edilen düşük emisyon seviyesi hedefine doğru ilerlemenin anlaşılabilmesi için ülkelerin ve kentlerin kapasitelerine ilişkin eylemlerini karşılaştıran bir analizlere ihtiyaç vardır. Birleşmiş Milletler İklim Değişikliği Çerçeve Sözleşmesi (BMIDÇS, https://unfccc.int) kapsamındaki potansiyel taahhüt ve yükümlülüklerini yerine getirmek için birçok ülke, sera gazı emisyonlarını azaltmak ve değişen iklime uyum sağlamak için stratejilerini tanımlayan ulusal iklim değişikliği eylem planları hazırlamaktadir.

$\mathrm{Bu}$ çalışma ormancılık sektörünün iki önemli konusu olan "havza yaklaşımı" ve "doğa temelli çözümler”e vurgu yaparak iklim değişikliği eylem planlarında ormancılığın rolünü irdelemeyi amaçlamaktadır.

Göç nedeniyle şehirlerin kalabalıklaşması, iklim değişikliği ile mücadeleyi bu yöne kaydırmayı gerektirmiştir (Forman ve Wu, 2016; UN, 2015). H1z11 kentleşme ile gelecekte enerji tüketimi ve sera gazı emisyonlarında genel bir artış eğilimi olması muhtemeldir. Büyüyen kentlerde önlem alınmazsa 2015 Paris İklim Anlaşması hedeflerine ulaşmak mümkün olmayabilir (Xu ve ark., 2019). Genellikle şehirlerde iklim değişikliğine uyum (adaptasyon) eylemlerinin merkezi hükümet politikalarından çok yerel yönetimlerin görevi olduğu düşünülmektedir. Ancak, adaptasyon yerel eylemle sinırlandırıldığında yetersiz kalabilir. İklim etkilerinin havza ölçeği ve sektörler arası politika ve planların doğası, genellikle daha büyük ölçekte (örn. orman yönetimi, doğa koruma, nehir havzası yönetimi, su yönetimi ve taşkın yönetimi gibi) koordinasyon gerektirir.

Çalışmamızda seçilen ülke ve kentlerin birçoğunda İklim Değişikliği Eylem Planının hazırlanmış olduğunu görüyoruz. Körfez ve Afrika bölgesinde seçilen şehirlerin büyük bir kısmında ise iklim değişikliği eylem planlarının olmadığı belirlenmiştir. Reckien ve ark. (2018) tarafından 885 Avrupa kentinde yapılan çalışmada küresel bazda sadece 147 şehrin İklim Değişikliği Eylem Planı olduğu ortaya konulmuştur. Alexander (2020), ABD eyaletlerine uyguladığı çalışmada 34 eyaletin İklim Eylem Planlarının hazırlanmış ve kabul edilmiş olduğunu ifade etmiştir. İklim stratejileri eyaletten eyalete farklılık göstermesine rağmen genelde ulaşım, arazi kullanımı, enerji, tarım, ormancılık ve atık gibi sektörlerden kaynaklanan sera gazı emisyonlarını azaltmaya yönelik bileşenler içermektedir. ABD eyaletlerinin iklim değişikliği ile mücadele yaklaşımları değerlendirildiğinde karbon emisyonlarının ölçülebilir fakat mütevazi azalmalara yol açtığını ortaya koymaktadır. Reckien ve ark. (2014) ise Avrupa şehirlerindeki yerel iklim planlarında azaltım konusunda sadece enerji sektörüne odaklanıldığını ifade etmiştir.

Araştırmamız, iklim eylem planlarında, iklim değişikliğinde azaltımın uyumdan daha çok dikkate aldığını ortaya koymuştur. Bunun başlıca üç nedeni olabilir;

- Uyum eylemlerinin azaltıma nazaran daha karmaşık olması,

- Uyum konusunun yeterince bilinmiyor olması,

- Gelişmiş ülklelerde azaltıma odaklanılmış olması.

Carmin ve ark. (2012)'nin farklı kıtalarda 468 şehirde yerel iklim planlamasındaki ilerlemeyi değerlendirdiği bir araştırmada şehirlerin adaptasyon uygulamalarında henüz erken bir aşamada olduğu ifade edilmiştir. Benzer bir araştırmada (Araos ve ark., 2016), küresel ölçekte 401 şehir değerlendi- 
rilmiş ve adaptasyon uygulamalarının daha az gelişmiş olduğu sonucuna varılmıştır. ABD'de 44 şehrin yerel uyum planları değerlendirildiğinde ise teorik olarak uyum eylemlerinin çerçevesi çizilmiş olmasına rağmen uygulamada aksaklıklar olduğu belirlenmiştir (Stults ve Woodruff, 2017; Woodruff ve Stults, 2016; Woodruff, 2018). Pietrapertosa ve ark. (2019) tarafından İtalya şehirlerinde yerel uyum iklim planları incelenmiş, yerel iklim değişikliği uyum planlarının yetersizliği ortaya konulmuştur. Baker ve ark. (2012) ise Avustralya'nın şehir yerel yönetimlerinin iklim uyum eylemlerini etkili bir şekilde planlayamadıklarını ortaya koymuştur.

Havza Yaklaşımı, seçilen ülke ve şehirlerde iklim değişikliği eylem planlarında ve/veya strateji belgelerinde yeterince yer almamaktadır. İklim Değişikliği Eylem Planlarında (İDEP) havza kavramı en fazla Afrika bölgesindeki ülkelerde tespit edilmiştir. Diğer ülkelerde (Okyanusya bölgesinde seçilen şehirler hariç) ise IDEP'de havza kavramı sınırlı düzeyde yer aldığı görülmüştür. Körfez bölgelerinde seçilen ülkelerde ise havza kavramı çok sınırlı oranda geçmiş, fakat bu bölgedeki şehirlerin IDEP'de havza kavramına rastlanmamıştır. Okyanusya bölgesinde seçilen ülkelerde havza kavramı geçmemesine rağmen şehirlerin İDEP'de büyük oranda havza kavramına rastlanmıştır. Diğer ülkelerde ise en fazla Kuzey Amerika bölgesinde seçilen şehirlerde havza kavramı büyük oranda geçmiş ve kalan şehirlerde havza kavramı küçük oranda tespit edilmiştir.

Doğa Temelli Çözümler (DTÇ), iklim değişikliğine uyum eylemlerinde ormancilıkla ilgili olup olmadığına baktığımızda ise Afrika, Körfez ve Okyanusya bölgelerinde seçilen ülkeler hariç diğer bölgelerde seçilen ülkelerde ağırlıklı olarak tespit edilmiştir. Güney Amerika, Afrika ve Körfez bölgelerinde seçilen şehirlerde ise İklim Değişikliği uyum eylemlerinde ormanc1lıkta doğa temelli çözümlere rastlanmamıştır.

Havza kavramı Türkiye'de seçilen şehirlerin IDEP'de araştırılmış ve seçilen şehirlerin çok küçük bir kısmında geçtiği görülmüştür. İklim Değişikliği Uyum Eylemlerinde ormancılıkla ilgili DTÇ'lere baktığımızda ise seçilen şehirlerin çok küçük bir kısmında yer aldığı tespit edilmiştir.

Ülkemizde mevcut yerel İDEP'lerin hem kapsam hem de içerik yönünden teknik anlamda yetersiz oldukları özellikle arazi kullanma ve ormancılık sektörünü yeterince ele almadıkları anlaşılmaktadır. Bu planlardaki eksiklik ve yetersizlikler sıralanacak olursa;
- Planlarda genellikle uyum ayağı eksik kalmakta veya hiç yer verilmemekte,

- İklim değişikliğine “uyum”un özünü iklim kaynaklı afetlerle mücadele oluşturmalıdır. Oysa, sel-taşkın ve benzeri aşırı hava olayları arazi kullanımı ile ilişkilendirilmemektedir. Çözüm önerileri de bu durumda yetersiz kalmaktadır. Aşırı hava olayları sonucu ortaya çıkabilecek olumsuzlukların etkileri havza yaklaşımı ile azaltılabilir. Dolayısıyla uyum politika önerileri geliştirilirken havza ölçeği ve yaklaşımı dikkate alınmalıdır,

- İklim değişikliği azaltım politikalarına konu olması gereken sera gazı envanter hesaplamalarında teknik anlamda yetersizlikler ve kapsam bakımından eksiklikler görülmektedir. Örneğin arazi kullanımı, arazi kullanım değişikliği ve ormancılıktan veya tarım sektöründen kaynaklanan sera gazı salım ve tutumları söz konusu sektörlerin karmaşık yapısı ve veri ihtiyacı nedeniyle hesaplanamamakta veya Seviye-1 düzeyinde kalmaktadir. Mevcut envanterlerde de yine arazi kullanımı emisyonları ulusal envanterle uyumlu şekilde değil uluslararası Seviye-1 hesaplarıyla yapılmaktadir,

- IDEP'lerde 2030 yılı ormancılık azaltım hedefi eksik veya hiç yer almamaktadır,

- IDEP'lerde havza kavramı ve doğa temelli çözümler çok az ya da hiç yer almamaktadır.

\section{Kaynaklar}

Alexander, S.E., 2020. Harnessing the opportunities and understanding the limits of state level climate action plans in the United States. 0264-2751 2020 Elsevier Ltd. https://doi.org/10.1016/j.cities.2020.102622. Cities 99 (2020) 102622. ScienceDirect 2020.

Altunok, A. E., Altunok, E., 2016. "AB iklim değişikliği politikaları”. Denetişim, 12: 45-55.

Araos, M., Berrang-Ford, L., Ford, J.D., Austin, S.E., Biesbroek, R., Lesnikowski, A., 2016. Climate change adaptation planning in large cities: a systematic global assessment. Environ. Sci. Pol. 66(2): 375-382. https:// doi.org/10.1016/j.envsci.2016.06.009.

Baker, I., Peterson, A., Brown, G., McAlpine, C., 2012. Local government response to the impacts of climate change: An evaluation of local climate adaptation plans. Landscape and Urban Planning, 107(2): 127-136. https://doi.org/10.1016/j. landurbplan.2012.05.009.

Bertoldi, P., Kona, A., Rivas, S., Dallemand, J. F., 2018. Towards a global comprehensive and transparent framework for cities and local governments enabling an effective contribution to the Paris Climate Agreement. Current opinion in environmental sustainability, 30: 67-74.

Carmin, J., Nadkarni N., Rhie, C., 2012. Progress and Challenges in Urban Climate Adaptation Planning: Re- 
sults of a Global Survey. Cambridge, MA, DUSP/MIT.

Cohen-Shacham, E., Andrade, A., Dalton, J., Dudley, N., Jones, M., Kumar, C., Maginnis, S., Maynard, S., Nelson, N. C., Renaud, F. G., Welling, R., Walters, G., 2019. Core principles for successfully implementing and upscaling Nature-based Solutions. Environmental Science Policy, 98: 20-29.

Demirci, M., 2015. "Kentsel iklim değişikliği yönetişimi". Erciyes Üniversitesi İktisadi ve İdari Bilimler Fakültesi Dergisi, 46: 75-100.

Forman, R.T., Wu, J., 2016. Where to put the next billion people. Nature News, 537(7622), 608

Grafakos S., Trigg K., Landauer M., Chelleri L., Dhakal S., 2019. Analytical framework to evaluate the level of integration of climate adaptation and mitigation in cities. Clim Change 2019:1-20. https://doi.org/10.1007/s10584019-02394-w.

Gunfaus, M.T., Waisman, H., (2021). Assessing the adequacy of the global response to the Paris Agreement: Toward a full appraisal of climate ambition and action. Earth System Governance, 100102.

IPCC, 2014. Intergovernmental Panel on Climate Change. Climate Change 2014: Synthesis Report. Contribution of Working Groups I, II and III to the Fifth Assessment Report of the Intergovernmental Panel on Climate Change [Core Writing Team, R.K. Pachauri and L.A. Meyer (eds.)]. IPCC, Geneva, Switzerland, 151 pp.

Kahraman, S., Șenol, P., 2018. "İklim Değișikliği: Küresel, Bölgesel ve Kentsel Etkileri”. Akademia Sosyal Bilimler Dergisi, 353-370.

Morgan, J. A., 2019. Rising atmospheric CO2 and global climate change: responses and management implications for grazing lands. In Grasslands: Developments opportunities perspectives, 235-260. CRC Press.

Oğuz, C. U., 2010. "İklim değişikliği ile mücadelede yerel yönetimlerin rolü: Seattle örneği”. Yönetim ve Ekonomi: Celal Bayar Üniversitesi İktisadi ve İdari Bilimler Fakültesi Dergisi, 17(2), 25-41.

Özel, M., Kılıç, S., 2006. "Küresel bir sorun olarak iklim değişikliği ve iklim politikaları”. İstanbul Üniversitesi Siyasal Bilgiler Fakültesi Dergisi, 34(2): 137-169.

Pietrapertosa, F., Salvia, M., Hurtado., S. D. G., d'Alonzo, V., Church, J. M., Geneletti, D., Francesco M., Reckien, D., 2019. Urban climate change mitigation and adaptation planning: Are Italian cities ready?. Cities, 91(2): 93-105.

Reckien, D., Salvia, M., Heidrich, O., Church, J.M., Pietrapertosa, F., De Gregorio-Hurtado, S., D’Alonzo, V., Foley, A., Simoes, S.G., Krkoška Lorencová, E., Orru, H., Orru, K., Wejs, A., Flacke, J., Olazabal, M., Geneletti, D., Feliu, E., Vasilie, S., Nador, C., Krook-Riekkola, A., Matosović, M., Fokaides, P.A., Ioannou, B.I., Flamos, A., Spyridaki, N.-A., Balzan, M.V., Fülöp, O., Paspaldzhiev, I., Grafakos, S., Dawson, R., 2018. How are cities planning to respond to climate change? Assessment of local climate plans from 885 cities in the EU-28.
J. Clean. Prod. 191(2): 207-219. https://doi.org/10.1016/j. jclepro.2018.03.220.

Reckien, D., Flacke, J., Dawson, R.J., Heidrich, O., Olazabal, M., Foley, A., Hamann, J.J.P., Orru, H., Salvia, M., De Gregorio Hurtado, S., Geneletti, D., Pietrapertosa, F., 2014. Climate change response in Europe: What's the reality? Analysis of adaptation and mitigation plans from 200 urban areas in 11 countries. Climatic Change 122(2): 331-340. https://doi.org/10.1007/s10584-013-0989-8.

Salvia, M., Reckien, D., Pietrapertosa, F., Eckersley, P., Spyridaki, N. A., Krook-Riekkola, A., ... Heidrich, O., 2021. Will climate mitigation ambitions lead to carbon neutrality? An analysis of the local-level plans of 327 cities in the EU. Renewable and Sustainable Energy Reviews, 135, 110253.

Serengil, Y. (2018). Climate Change and Carbon Management: Agriculture, Forests and Other Land Uses. UNDP. www.tr.undp.org > dam > turkey > undp iklim_web

Stults, M., Woodruff, S.C., 2017. Looking under the hood of local adaptation plans: Shedding light on the actions prioritized to build local resilience to climate change. Mitigation and Adaptation Strategies for Global Change, 22(8), 1249-1279.

Sunde, M.G., He, H. S., Hubbart, J.A., Urban, M.A., 2018. An integrated modeling approach for estimating hydrologic responses to future urbanization and climate changes in a mixed-use midwestern watershed. Journal of Environmental Management, 220(2): 149-162.

T.C. Cevre ve Sehircilik Bakanlığ 1 (2010-2023). "Türkiye İklim Değişikliği Stratejisi”. Ankara

T.C. Çevre ve Şehircilik Bakanlığı (2011-2023). "İklim Değişikliği Uyum Stratejisi ve Eylem Planı”. Ankara

Thompson, I., Mackey, B., McNulty, S., Mosseler, A., 2009. Forest Resilience, Biodiversity, and Climate Change. A synthesis of the biodiversity/resilience/stability relationship in forest ecosystems. Secretariat of the Convention on Biological Diversity, Montreal. Technical Series no. 43, 67 pages. Canada.

Xu, L., Wang, X., Liu, J., He, Y., Tang, J., Nguyen, M., Cui, S., 2019. Identifying the trade-offs between climate change mitigation and adaptation in urban land use planning: an empirical study in a coastal city. Environ. Int. 133,105162

UN, 2015. United Nations. Resolution adopted by the general assembly on 25 september 2015. Transforming our world: The 2030 agenda for sustainable development. New York: UN: n.d.

WAH, 2014. Watershed Approach Handbook. Improving outcomes and increasing benefits associated with wetland and stream restoration and protection projects. The Environmental Law Institute (ELI) and The Nature Conservancy.

Wang, J., Gao, Y., Wang, S., 2018. Assessing the response of runoff to climate change and human activities for a typical basin in the Northern Taihang Mountain, China. Journal of Earth System Science, 127(3): 1-15. 
Woodruff SC., Stults M., 2016. Numerous strategies but limited implementation guidance in US local adaptation plans. Nat. Clim. Change 2016; 6(2):796-802. https://doi. org/10. 1038/nclimate3012.

Woodruff SC., 2018 City membership in climate change adaptation networks. Environ. Sci. Policy 2018; 84:60-
81. https://doi.org/10.1016/j.envsci.2018.03.002.

Zölch, T., Maderspacher, J., Wamsler, C., Pauleit, S., 2016. Using green infrastructure for urban climate-proofing: An evaluation of heat mitigation measures at the micro-scale. Urban Forestry Urban Greening, 20(2): 305-316. 